\title{
Development of Weather-Resistant 3D Printed Structures by Multi-Material Additive Manufacturing
}

\author{
Arash Afshar* and Roy Wood \\ School of Engineering, Mercer University, Macon, GA 31207, USA; Roy.Andrew.Wood@live.mercer.edu \\ * Correspondence: afshar_a@mercer.edu; Tel.: +1-478-301-2421
}

Received: 11 June 2020; Accepted: 16 July 2020; Published: 18 July 2020

\begin{abstract}
Additive manufacturing, or 3D printing, has had a big impact on the manufacturing world through its low cost, material recyclability, and fabrication of intricate geometries with a high resolution. Three-dimensionally printed polymer structures in aerospace, marine, construction, and automotive industries are usually intended for service in outdoor environments. During long-term exposures to harsh environmental conditions, the mechanical properties of these structures can be degraded significantly. Developing coating systems for 3D printed parts that protect the structural surface against environmental effects and provide desired surface properties is crucial for the long-term integrity of these structures. In this study, a novel method was presented to create 3D printed structures coated with a weather-resistant material in a single manufacturing operation using multi-material additive manufacturing. One group of specimens was 3D printed from acrylonitrile-butadiene-styrene (ABS) material and the other group was printed from ABS and acrylic-styrene-acrylonitrile (ASA) as a substrate and coating material, respectively. The uncoated ABS specimens suffered significant degradation in the mechanical properties, particularly in the failure strain and toughness, during exposure to UV radiation, moisture, and high temperature. However, the ASA coating preserved the mechanical properties and structural integrity of ABS 3D printed structures in aggressive environments.
\end{abstract}

Keywords: 3D printed coating; multi-material additive manufacturing; environmental exposure; ABS; ASA

\section{Introduction}

Additive manufacturing (AM) has numerous applications, ranging from medicinal delivery to aerospace, automotive systems, construction, biodegradable solutions, and ever-expanding technologies as a platform for innovative designs [1-4]. Three-dimensional printing technology found its way into different industries through a variety of techniques such as powder bed fusion, inkjet printing, direct energy deposition, and laminated object manufacturing [5,6]. Given the expanding range of processes, the scope of solutions has likewise expanded, from the 3D printing of shape-memory materials in the development of aerospace deployable equipment in solar panels and antennas [3], and thermoplastic equipment that can be printed on board the international space station, to manufacturing of biodegradable scaffolds for organ growth, and direct printing of organs and tissues [7]. The process has been adopted as one of the industrial requirements for technology and scientific research. The most common method of 3D printing is fused deposition modeling (FDM). In this technique, a thermoplastic material, typically in the form of continuous filaments, is heated and then extruded through a nozzle into several layers to form the final object as it is being cooled down [8-13].

Polymer matrix 3D printed structures, like other types of polymer-based structure, are susceptible to environmental exposure, such as ultraviolet (UV) radiation, moisture, or heat. The diffusion of moisture into the structural components can damage the material as a result of the change in the 
mechanical properties of the polymer or replacing or weakening matrix-reinforcement interfacial bonds through irreversible hydrolysis and plasticization [14,15]. Ultraviolet photons from sunlight exposure initiate photo-oxidative reactions (i.e., chains scission and chain crosslinking) which deteriorate polymer materials by altering their chemical structures. Chain scission reduces the molecular weight of the polymer, which in turn degrades its strength and heat resistance. Chain cross-linking enhances the brittleness of the polymer, leading to the surface microcracking [16-19]. The synergistic environmental exposures can be more detrimental than individual exposures acting alone. For instance, in outdoor environments, moisture diffuses into polymer materials and occupies positions among the polymer molecules that results in the swelling of polymers. The moisture-induced damage will be exacerbated by microcracking formation during UV exposure, which facilitates the moisture diffusion into polymers. Moisture also dissolves and removes products of photo-oxidative reactions and exposes a fresh surface for further degradation by UV radiation [20-22]. The adverse effect of moisture increases at elevated temperatures as a result of an increase in the rate of water absorption into polymer-based structures $[23,24]$.

Nowadays, 3D printers can create multi-material objects with desired properties in specific locations. By the advancement of AM processes, the creation of multifunctional parts becomes feasible, which has never been possible through traditional, single-material manufacturing methods. This unique AM feature is possible through layer-by-layer placement of material in the specific areas, which enables the manufacturer to control structural properties at exact locations and tailor them for specific applications [25-27]. Multi-material additive manufacturing can produce coatings with certain properties on the surface of 3D printed structures, and it is a great replacement for conventional ways of painting structures, such as brushing and air-spraying, or recently developed methods for metallization of structural surface that are more costly and time-consuming [28]. The compatibility between 3D printing materials as well as the printing parameters such as nozzles' temperatures and printing speed are important factors in creating a strong adhesion between 3D printed layers with distinct material properties using multi-material additive manufacturing methods [5,25].

ABS, or acrylonitrile-butadiene-styrene, has seen the largest commercial usage in the additive manufacturing industry due to its rigidity and high mechanical performance. ABS can be used to create objects with intricate designs, structures with moving parts, and structures that are aimed for further plastic forming, without the risk of breakage. However, it has been reported that the mechanical properties of 3D printed ABS structures can diminish significantly during exposure to harsh environmental conditions [28-30]. ASA, or acrylic-styrene-acrylonitrile, is a weather-resistant thermoplastic material with a high performance in outdoor environmental conditions, including UV radiation, moisture, and high temperatures. It offers easy printing, good dimensional stability, and an excellent layer to layer adhesion.

In this paper, the surfaces of ABS 3D printed structures were coated by weather-resistant ASA using a multi-material additive manufacturing technique to enhance the durability of the structure in aggressive environments. The current study offers insights for the design, coating, and maintenance of 3D printed polymer structures exposed to outdoor environmental conditions.

\section{Experimental Methods and Materials}

A Raise3D Pro2 dual extruder 3D printer (Raise3D, Irvine, CA, USA) was employed to produce samples from eSUN ABS and FilamentOne ASA PRO SELECT filaments using the FDM method. Three-dimensionally printed specimens had dimensions according to the ASTM D790 standard of $127 \mathrm{~mm}$ (length) $\times 12.7 \mathrm{~mm}$ (width) $\times 3.2 \mathrm{~mm}$ (thickness). Nozzles with a size of $0.4 \mathrm{~mm}$ were used for 3D printing of specimens and nozzles' temperatures were established to be $205{ }^{\circ} \mathrm{C}$ for $\mathrm{ABS}$ and $220{ }^{\circ} \mathrm{C}$ for ASA extrusion. The bed temperature and the infill density were set to $100{ }^{\circ} \mathrm{C}$ and $100 \%$, respectively. The bed temperature is the temperature of the platform where the object is $3 \mathrm{D}$ printed. The infill density determines the distance between adjacent deposited filaments within the shell of the printed structure and an infill density of $100 \%$ results in no air gaps between adjacent filaments. 
The shell is the outer wall of the printed object that outlines the desired shape of the printed structure and provides an anchor for the infill deposition. The print pattern was set to alternating angles (i.e., periodic $-45^{\circ} \%+45^{\circ}$ ) of layer deposition with solid edges to create identical mechanical properties in longitudinal and transverse directions of specimens, as illustrated in Figure 1. The pattern was printed with an inner shell speed of $70 \mathrm{~mm} / \mathrm{s}$, outer shell speed of $25 \mathrm{~mm} / \mathrm{s}$, and infill speed of $80 \mathrm{~mm} / \mathrm{s}$. The layer height for the deposition of ABS and ASA filaments was set to 0.3 and $0.125 \mathrm{~mm}$, respectively. The layer height is the thickness of the deposited filament per pass. In ASA-coated ABS specimens, ASA coating with a thickness of $0.25 \mathrm{~mm}$ that consists of 2 layers was deposited on both sides of specimens. One of the advantages of AM compared to traditional manufacturing techniques is the ability to combine dissimilar materials in one continuous process, which eliminates the requirement of using intermediate adhesives for bonding two distinctive materials. The thickness of ASA coating was taken into consideration during 3D printing in order to manufacture uncoated and ASA-coated ABS specimens with the same thickness.

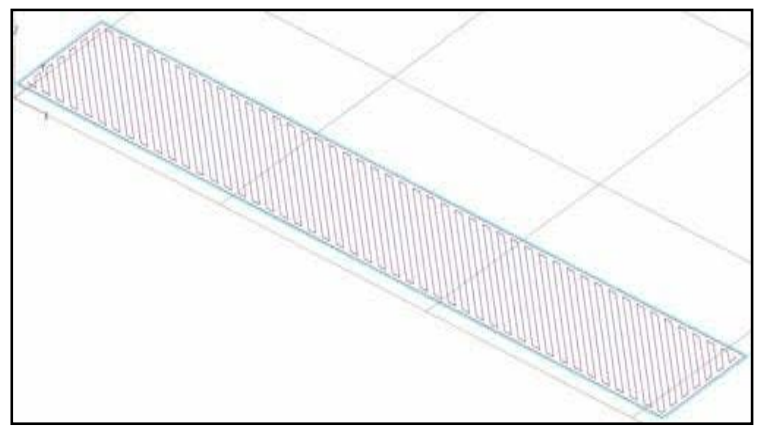

(a)

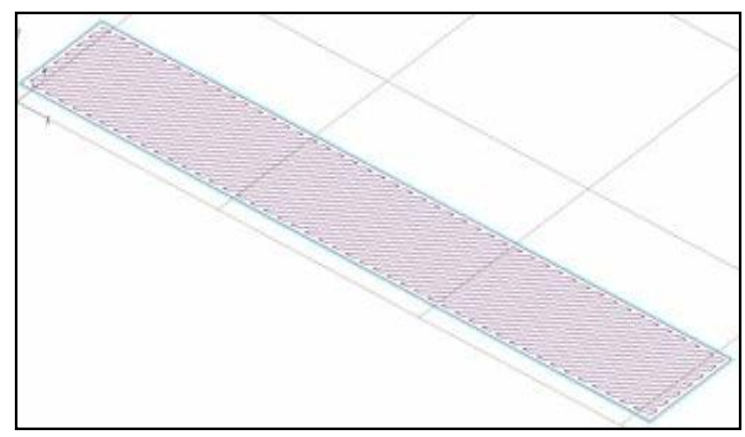

(b)

Figure 1. Deposition of the (a) first and (b) second layers during 3D printing of specimens to create a pattern of alternating $-45^{\circ} /+45^{\circ}$ angles.

To simulate the effects of outdoor environmental conditions on 3D printed polymer structures, ABS samples with or without an ASA coating layer were aged in a controlled environmental chamber. Exposure to UV radiation and moisture was conducted by using a UV radiation/condensation (Q-Lab QUV/basic) accelerated weathering tester. In the environmental chamber, the specimens were exposed to UV radiation and moisture cycles. UV radiation was generated with $340 \mathrm{~nm}$ wavelength UVA lights set at $0.89 \mathrm{~W} / \mathrm{m}^{2}$ intensity and $60^{\circ} \mathrm{C}$ chamber temperature. The condensation was produced by condensing vapor on specimens in the environmental chamber with $100 \%$ humidity and a temperature of $50{ }^{\circ} \mathrm{C}$. To follow the ASTM G154 standard and create a synergistic exposure to both UV radiation and moisture, specimens were cyclically exposed to $8 \mathrm{~h}$ of $\mathrm{UV}$ radiation followed by $4 \mathrm{~h}$ condensation.

The LEO 1530 Scanning Electron Microscope (Zeiss, White Plains, NY, USA) and VHX 6000 Keyence Digital Microscope (Keyence, Itasca, IL, USA) were used to characterize the surface morphology of specimens during environmental exposure. A $5 \mathrm{~nm}$ gold layer was deposited on samples via a Quorum sputter coater before SEM analysis and scanning electron microscopy was carried out with the beam accelerating voltage of $5 \mathrm{kV}$. The resistance of ASA coating to separation from the ABS substrate before and after environmental aging was assessed according to ISO 2409 standard. The flexural properties of specimens during environmental exposure were evaluated using the three-point bending test carried out by using Mark-10 testing equipment after 0, 300, 600, and $1200 \mathrm{~h}$ of environmental aging. The span length of $51.2 \mathrm{~mm}$ (span to depth ratio of 16:1) and the crosshead rate of $1.37 \mathrm{~mm} / \mathrm{min}$ were used to produce a strain rate of $0.01 \mathrm{~mm} / \mathrm{mm} / \mathrm{min}$ in specimens based on the ASTM D790 standard. Six specimens per each condition were used to ensure the reproducibility of results. 


\section{Results and Discussion}

\subsection{Surface Analysis}

During service, 3D printed polymer structures are typically exposed to aggressive environmental conditions that may lead to the initiation and propagation of surface damage and eventually failure of the entire structure under loading conditions. Therefore, investigation of the surface microstructure of $3 \mathrm{D}$ printed parts is necessary to evaluate their performance in outdoor environments.

The digital microscopy images of the surface of uncoated ABS samples before and after $1200 \mathrm{~h}$ of exposure to UV radiation and moisture are given in Figure 2a,b. The yellowing of the surface areas due to UV radiation and the creation of surface microcracks can be observed in Figure $2 b$. The cyclic temperature variation inside the environmental chamber produces thermal stresses in the specimens, which facilitates the creation and propagation of microcracks on the UV-exposed surfaces. Figure $3 a, b$ present the surface microscopy images of ASA-coated ABS specimens before and after environmental aging. It can be observed that the ASA coating provides good protection for the underlying ABS specimen and no microcracking was observed on the specimen's surface.

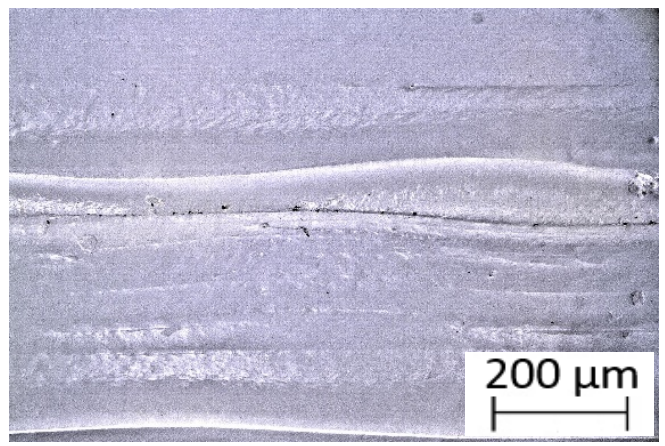

(a)

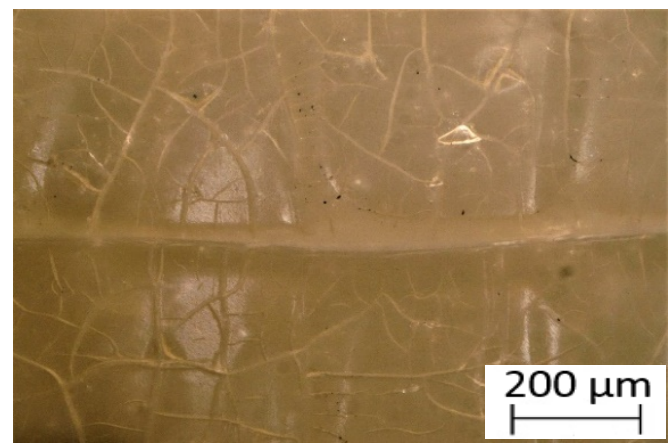

(b)

Figure 2. Digital microscopy images of the surface of uncoated acrylonitrile-butadiene-styrene (ABS) specimen (a) before and (b) after $1200 \mathrm{~h}$ of exposure to UV radiation and moisture.

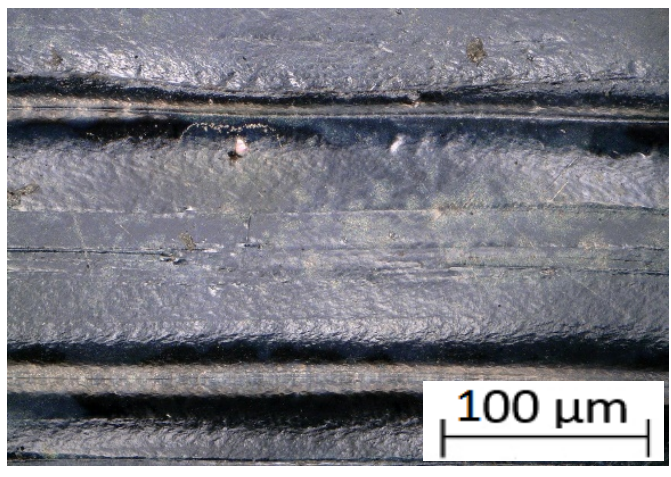

(a)

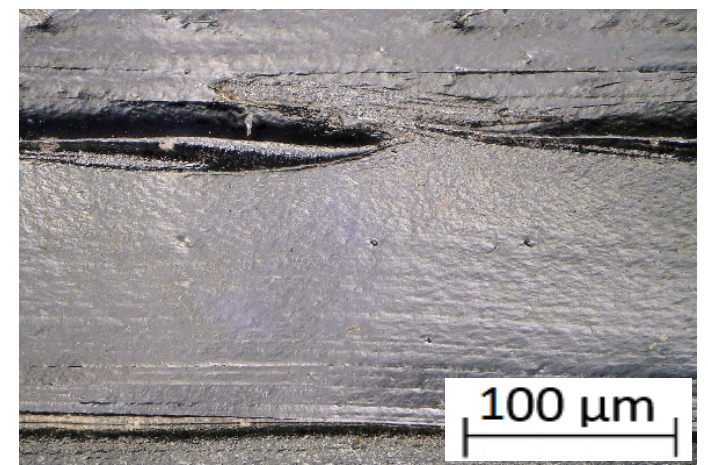

(b)

Figure 3. Digital microscopy images of the surface of acrylic-styrene-acrylonitrile (ASA)-coated ABS specimen (a) before and (b) after $1200 \mathrm{~h}$ of exposure to UV radiation and moisture.

To better assess the damage in the specimens after environmental aging, scanning electron microscopy (SEM) images of the surface area of uncoated and ASA-coated ABS samples before and after environmental exposure are presented in Figures 4 and 5. It can be seen that an extensive propagation of microcracking occurred on the surface of the uncoated specimen after $1200 \mathrm{~h}$ of environmental aging. The UV-induced microcracks and a high-temperature environment facilitate the 
ingression of moisture into 3D printed polymer structures that can have detrimental effects on the long-term durability of structures.

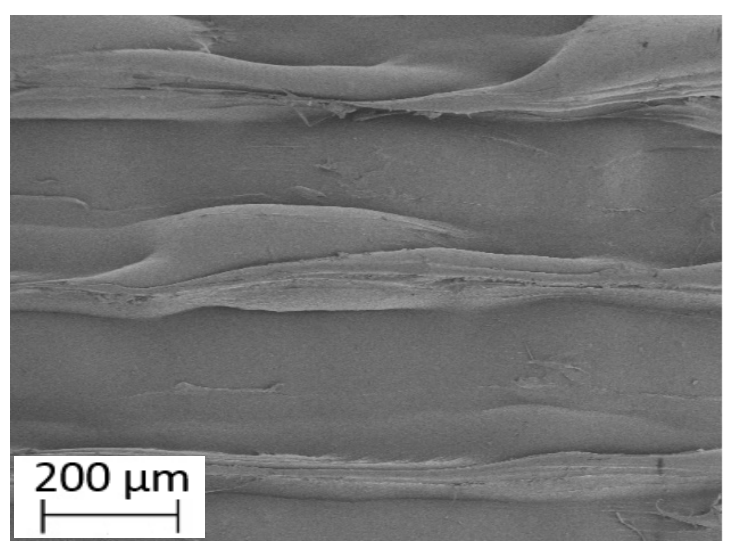

(a)

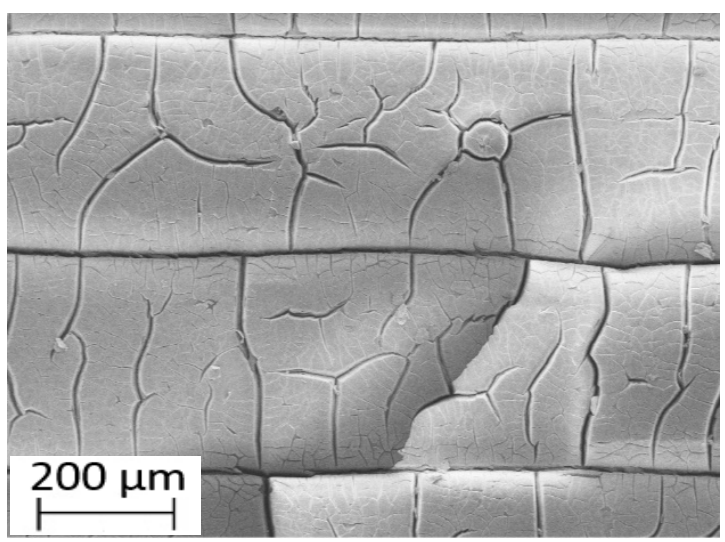

(b)

Figure 4. SEM images of the surface of uncoated ABS specimen (a) before and (b) after $1200 \mathrm{~h}$ of exposure to UV radiation and moisture.

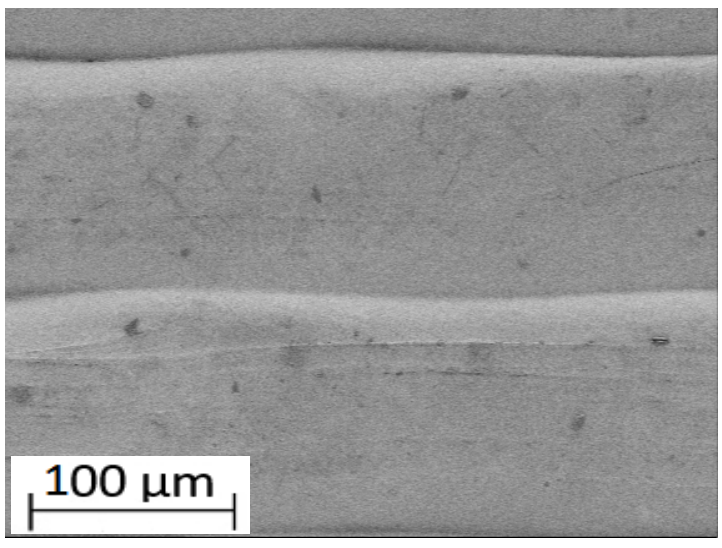

(a)

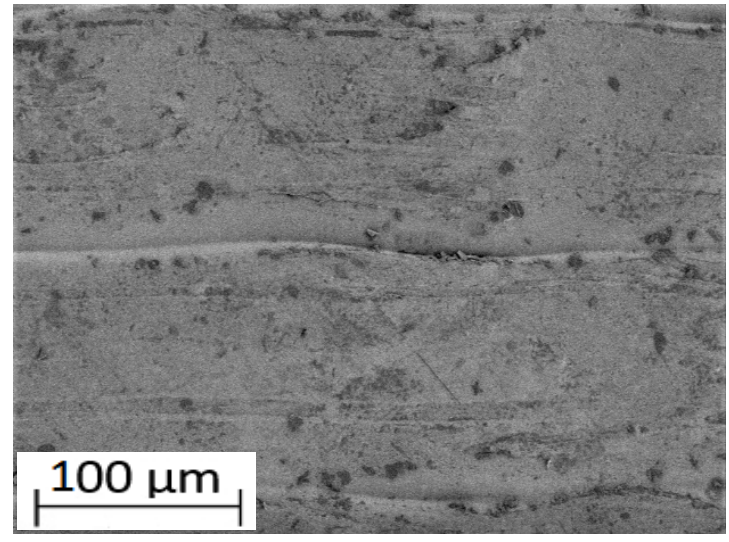

(b)

Figure 5. SEM images of the surface of ASA-coated ABS specimen (a) before and (b) after $1200 \mathrm{~h}$ of exposure to UV radiation and moisture.

The environmental exposure has no noticeable effects on the surface microstructure of ASAcoated ABS specimens, as illustrated in Figure 5b. No observable microcracks were generated on the structural surface and the ASA-coated ABS specimen retained its structural integrity throughout the exposure.

A robust interfacial adhesion between the coating and the substrate is essential for the durability of $3 \mathrm{D}$ printed structures created by multi-material additive manufacturing. The strength of the adhesion bond between the ASA coating and ABS substrate before and after $1200 \mathrm{~h}$ of environmental aging was examined according to ISO 2409 standard. The adhesion test was performed on ASA-coated ABS 3D printed samples with dimensions of $60 \mathrm{~mm}$ (length) $\times 60 \mathrm{~mm}$ (width) $\times 3.2 \mathrm{~mm}$ (thickness). Since the thickness of the ASA coating is $0.25 \mathrm{~mm}$, six cuts with $3 \mathrm{~mm}$ spacing were created along the length and width directions following the standard.

No separation of ASA coating was observed after the removal of adhesive tape from the surface of both environmentally aged and unexposed specimens. The adhesion of ASA coating to the ABS substrate was classified as grade 0 based on the ISO 2409 standard, demonstrating the highest level of resistance of the coating to the separation from the substrate that remained unaffected during the environmental aging. 


\subsection{Flexural Response}

Out-of-plane loading is one of the main forces that acts on the structural components in outdoor environments. This requires a thorough investigation of the flexural response of $3 \mathrm{D}$ printed polymer structures under the bending load. Figure 6a shows that the flexural modulus of ABS specimens with or without ASA coating was relatively unchanged during the environmental exposure. This can be attributed to the fact that modulus is a bulk material property, while the environmental effect is primarily a surface phenomenon. The embrittlement of polymers on the surface area due to UV radiation can cause a slight increase in the modulus of specimens, as illustrated in Figure 6a.

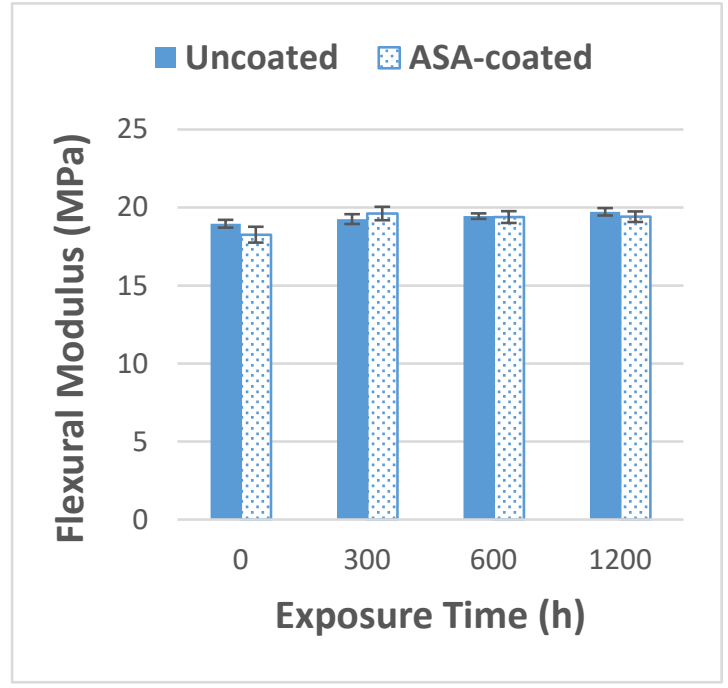

(a)

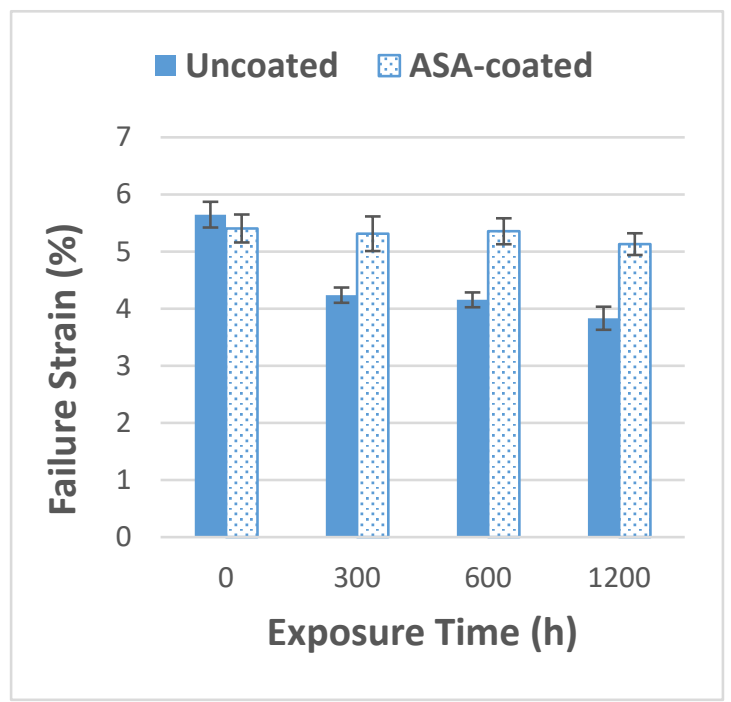

(c)

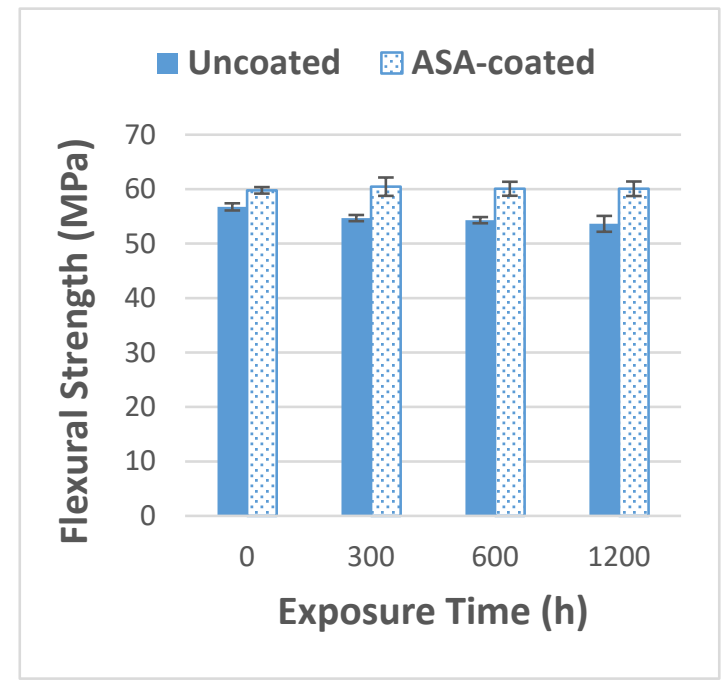

(b)

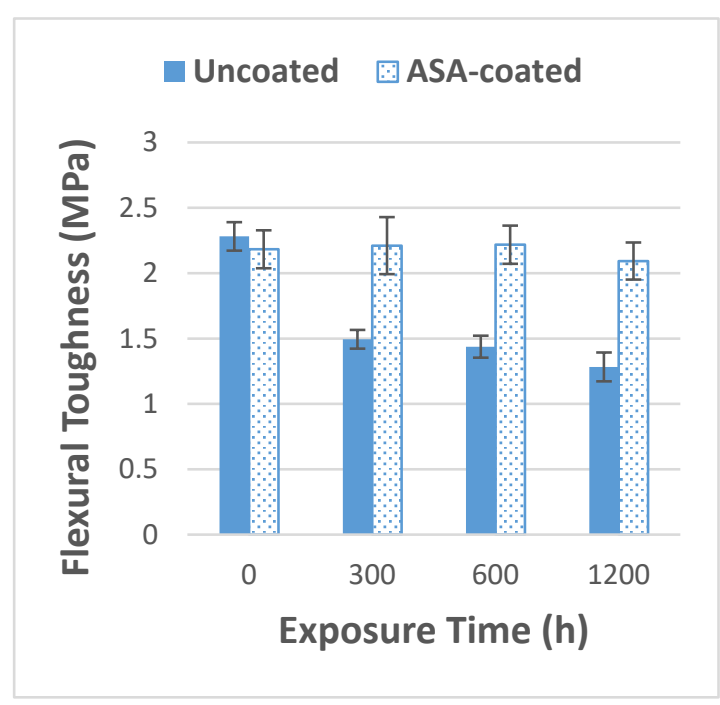

(d)

Figure 6. Flexural properties of uncoated and ASA-coated 3D printed ABS samples during exposure to UV radiation and moisture. (a) Flexural modulus; (b) flexural strength; (c) failure strain; (d) flexural toughness.

Figure $6 \mathrm{~b}$ demonstrates that uncoated ABS specimens lost $5.5 \%$ of their flexural strength throughout the exposure, while no noticeable changes in the flexural strength of ASA-coated ABS specimens were observed. The failure strain of specimens over the exposure time is given in Figure $6 \mathrm{c}$. The failure strain of uncoated specimens decreased significantly during exposure to UV radiation and moisture 
with a maximum reduction of $32.1 \%$ after $1200 \mathrm{~h}$ of environmental aging. However, the ductility of ASA-coated specimens showed a slight reduction throughout the exposure, with a maximum decrease of $5.1 \%$. This can be attributed to the extensive propagation of microcracks on the surface areas of uncoated ABS specimens that can significantly impair the elongation in the outer layers which are subjected to maximum tensile stresses.

Flexural toughness was measured as the integral of the area under the stress-strain curves of samples during the three-point bending test. Figure $6 \mathrm{~d}$ shows that the flexural toughness is the most susceptible mechanical properties of uncoated 3D printed ABS specimens to the environmental aging with a maximum reduction of $43.8 \%$ after $1200 \mathrm{~h}$ of exposure to UV radiation and moisture. The ASA-coated ABS specimens could significantly preserve their flexural toughness after $1200 \mathrm{~h}$ of environmental exposure with a retention of $95.9 \%$ of the initial flexural toughness. Figure 7 presents the average stress-strain curves of uncoated and ASA-coated ABS specimens after 0, 300, 600, and $1200 \mathrm{~h}$ of environmental exposure that are obtained from the flexural test. It can be observed that both uncoated and ASA-coated ABS specimens show ductile failure before and after environmental aging. The significant reduction in the flexural toughness of uncoated specimens was a result of a decrease in both flexural strength and ductility of specimens that largely reduced the area under the stress-strain curves, as observed in Figure 7.

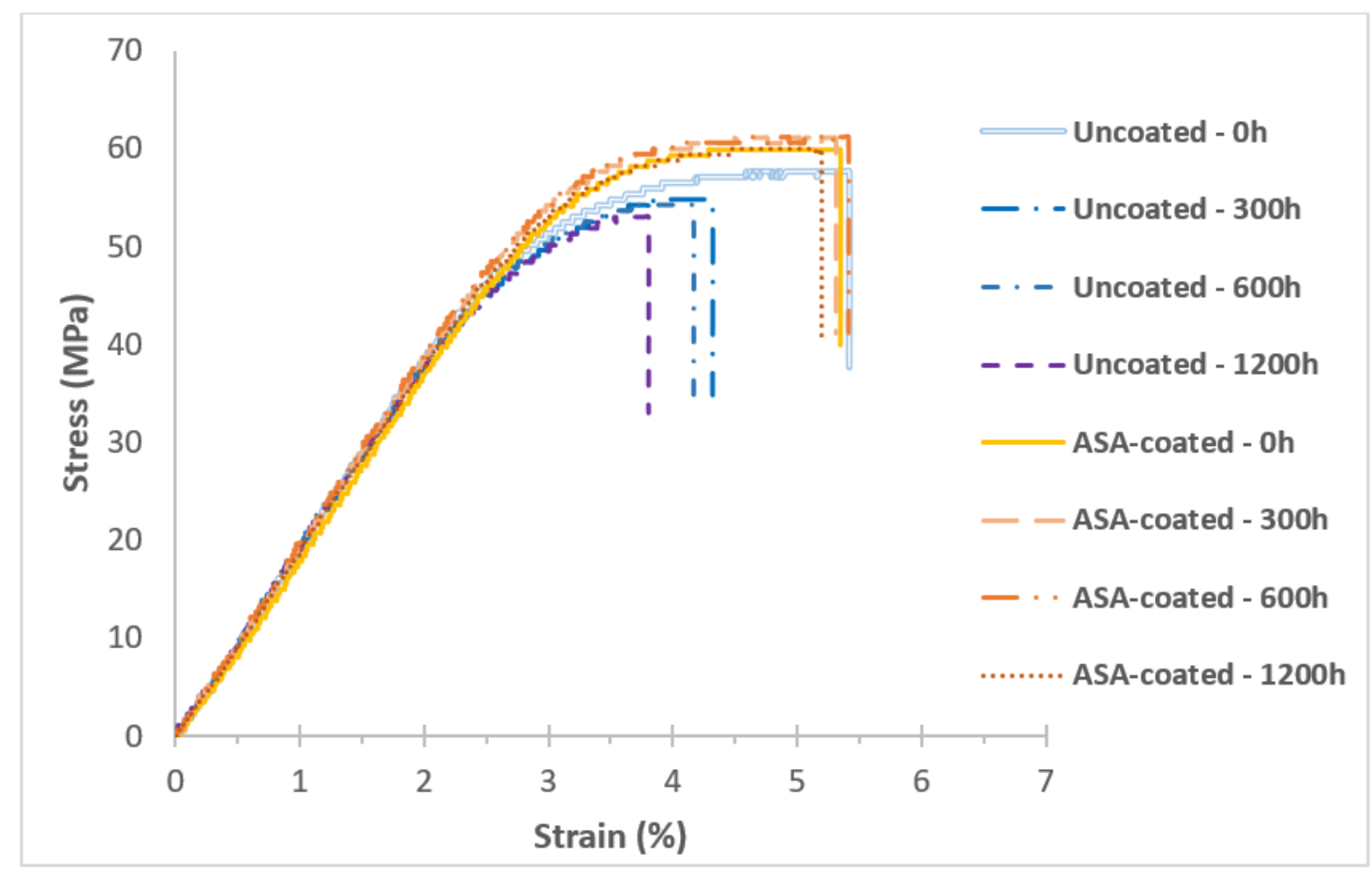

Figure 7. The average stress-strain curves of uncoated and ASA-coated 3D printed ABS specimens after $0,300,600$, and $1200 \mathrm{~h}$ of environmental exposure to UV radiation and moisture.

\section{Conclusions}

Developing coating systems for 3D printed polymer structures that protect the structural surface against aggressive environmental conditions is critical for the long-term durability of the structures. In this study, multi-material 3D printing was used to deposit an ASA coating on the surface of ABS structures to protect the structure against UV radiation, moisture, and heat. The uncoated ABS samples suffered significant degradation in the mechanical properties, particularly in the failure strain and toughness, during environmental aging. However, ASA-coated ABS specimens largely retained their initial mechanical properties throughout the environmental exposure. 
Author Contributions: Data curation and Investigation, R.W.; Conceptualization and Writing-original draft, A.A. All authors have read and agreed to the published version of the manuscript.

Funding: This research received no external funding.

Acknowledgments: The authors would like to thank Provost Office at Mercer University for the SEED grant and the support of this work.

Conflicts of Interest: The authors declare no conflict of interest.

\section{References}

1. Dey, A.; Yodo, N. A Systematic Survey of FDM Process Parameter Optimization and Their Influence on Part Characteristics. J. Manuf. Mater. Process. 2019, 3, 64. [CrossRef]

2. Ahn, S.-H.; Montero, M.; Odell, D.; Roundy, S.; Wright, P.K. Anisotropic material properties of fused deposition modeling ABS. Rapid Prototyp. J. 2002, 8, 248-257. [CrossRef]

3. Mitchell, A.; Lafont, U.; Hołyńska, M.; Semprimoschnig, C.J.A.M. Additive manufacturing-A review of 4D printing and future applications. Addit. Manuf. 2018, 24, 606-626. [CrossRef]

4. Perez, A.R.T.; Roberson, D.A.; Wicker, R.B. Fracture Surface Analysis of 3D-Printed Tensile Specimens of Novel ABS-Based Materials. J. Fail. Anal. Prev. 2014, 14, 343-353. [CrossRef]

5. Ngo, T.; Kashani, A.; Imbalzano, G.; Nguyen, Q.T.; Hui, D. Additive manufacturing (3D printing): A review of materials, methods, applications and challenges. Compos. Part B Eng. 2018, 143, 172-196. [CrossRef]

6. Conner, B.P.; Manogharan, G.P.; Martof, A.N.; Rodomsky, L.M.; Rodomsky, C.M.; Jordan, D.C.; Limperos, J.W. Making sense of 3-D printing: Creating a map of additive manufacturing products and services. Addit. Manuf. 2014, 1, 64-76. [CrossRef]

7. Yan, Q.; Dong, H.-H.; Su, J.; Han, J.; Song, B.; Wei, Q.; Shi, Y. A Review of 3D Printing Technology for Medical Applications. Engineering 2018, 4, 729-742. [CrossRef]

8. Ning, F.; Cong, W.; Qiu, J.; Wei, J.; Wang, S. Additive manufacturing of carbon fiber reinforced thermoplastic composites using fused deposition modeling. Compos. Part B Eng. 2015, 80, 369-378. [CrossRef]

9. Christiyan, K.J.; Chandrasekhar, U.; Venkateswarlu, K. A study on the influence of process parameters on the Mechanical Properties of 3D printed ABS composite. IOP Conf. Ser. Mater. Sci. Eng. 2016, 114, 012109. [CrossRef]

10. Sanatgar, R.H.; Campagne, C.; Nierstrasz, V. Investigation of the adhesion properties of direct 3D printing of polymers and nanocomposites on textiles: Effect of FDM printing process parameters. Appl. Surf. Sci. 2017, 403, 551-563. [CrossRef]

11. Huang, B.; Singamneni, S. Raster angle mechanics in fused deposition modelling. J. Compos. Mater. 2014, 49, 363-383. [CrossRef]

12. Ning, F.; Cong, W.; Hu, Y.; Wang, H. Additive manufacturing of carbon fiber-reinforced plastic composites using fused deposition modeling: Effects of process parameters on tensile properties. J. Compos. Mater. 2016, 51, 451-462. [CrossRef]

13. Wei, X.; Li, D.; Jiang, W.; Gu, Z.; Wang, X.; Zhang, Z.; Sun, Z. 3D Printable Graphene Composite. Sci. Rep. 2015, 5, 11181. [CrossRef] [PubMed]

14. Loos, A.C.; Springer, G.S. Moisture Absorption of Graphite-Epoxy Composites Immersed in Liquids and in Humid Air. J. Compos. Mater. 1979, 13, 131-147. [CrossRef]

15. Wright, W. The effect of diffusion of water into epoxy resins and their carbon-fibre reinforced composites. Composites 1981, 12, 201-205. [CrossRef]

16. Yousif, E.; Haddad, R. Photodegradation and photostabilization of polymers, especially polystyrene. SpringerPlus 2013, 2, 1-32. [CrossRef] [PubMed]

17. Signor, A.W.; VanLandingham, M.R.; Chin, J.W. Effects of ultraviolet radiation exposure on vinyl ester resins: Characterization of chemical, physical and mechanical damage. Polym. Degrad. Stab. 2003, 79, 359-368. [CrossRef]

18. Rånby, B. Photodegradation and photo-oxidation of synthetic polymers. J. Anal. Appl. Pyrolysis 1989, 15, 237-247. [CrossRef]

19. Afshar, A.; Mihut, D.; Baqersad, J.; Hill, S. Study of metallic thin films on epoxy matrix as protective barrier to ultraviolet radiation. Surf. Coat. Technol. 2019, 367, 41-48. [CrossRef] 
20. Afshar, A.; Liao, H.-T.; Chiang, F.-P.; Korach, C.S. Time-dependent changes in mechanical properties of carbon fiber vinyl ester composites exposed to marine environments. Compos. Struct. 2016, 144, 80-85. [CrossRef]

21. Afshar, A.; AlKhader, M.; Korach, C.S.; Chiang, F.-P. Effect of long-term exposure to marine environments on the flexural properties of carbon fiber vinylester composites. Compos. Struct. 2015, 126, 72-77. [CrossRef]

22. Afshar, A.; Mihut, D.; Chen, P. Effects of environmental exposures on carbon fiber epoxy composites protected by metallic thin films. J. Compos. Mater. 2019, 54, 167-177. [CrossRef]

23. Ray, B.C. Temperature effect during humid ageing on interfaces of glass and carbon fibers reinforced epoxy composites. J. Colloid Interface Sci. 2006, 298, 111-117. [CrossRef] [PubMed]

24. Eftekhari, M.; Fatemi, A. Tensile behavior of thermoplastic composites including temperature, moisture, and hygrothermal effects. Polym. Test. 2016, 51, 151-164. [CrossRef]

25. Bandyopadhyay, A.; Heer, B. Additive manufacturing of multi-material structures. Mater. Sci. Eng. R Rep. 2018, 129, 1-16. [CrossRef]

26. Huang, S.H.; Liu, P.; Mokasdar, A.; Hou, L. Additive manufacturing and its societal impact: A literature review. Int. J. Adv. Manuf. Technol. 2012, 67, 1191-1203. [CrossRef]

27. Tibbits, S. 4D Printing: Multi-Material Shape Change. Arch. Des. 2014, 84, 116-121. [CrossRef]

28. Afshar, A.; Mihut, D. Enhancing durability of 3D printed polymer structures by metallization. J. Mater. Sci. Technol. 2020, 53, 185-191. [CrossRef]

29. Santos, R.M.; Botelho, G.; Machado, A.V. Artificial and natural weathering of ABS. J. Appl. Polym. Sci. 2010, 116, 2005-2014. [CrossRef]

30. Perez, J.M.; Vilas, J.L.; Laza, J.M.; Arnaiz, S.; Mijangos, F.; Bilbao, E.; León, L.M. Effect of Reprocessing and Accelerated Weathering on ABS Properties. J. Polym. Environ. 2009, 18, 71-78. [CrossRef]

(C) 2020 by the authors. Licensee MDPI, Basel, Switzerland. This article is an open access article distributed under the terms and conditions of the Creative Commons Attribution (CC BY) license (http://creativecommons.org/licenses/by/4.0/). 